\title{
Bond Behavior of Wet-Bonded Carbon Fiber-Reinforced Polymer-Concrete Interface Subjected to Moisture
}

\author{
Yiyan Lu (D), Tao Zhu $\mathbb{D}^{D}$, Shan Li $(\mathbb{D}$, and Zhenzhen Liu \\ School of Civil Engineering, Wuhan University, Wuhan 430072, China \\ Correspondence should be addressed to Shan Li; lishan@whu.edu.cn \\ Received 10 October 2017; Revised 9 January 2018; Accepted 13 February 2018; Published 14 March 2018 \\ Academic Editor: Young Hoon Kim
}

Copyright ( 2018 Yiyan Lu et al. This is an open access article distributed under the Creative Commons Attribution License, which permits unrestricted use, distribution, and reproduction in any medium, provided the original work is properly cited.

\begin{abstract}
The use of carbon fiber-reinforced polymer (CFRP) composite materials to strengthen concrete structures has become popular in coastal regions with high humidity levels. However, many concrete structures in these places remain wet as a result of tides and wave-splashing, so they cannot be completely dried before repair. Therefore, it is vital to investigate the effects of moisture on the initial and long-term bond behavior between CFRP and wet concrete. This research assesses the effects of moisture (i) during CFRP application and (ii) throughout the service life. Before CFRP bonding, the concrete blocks are preconditioned with a water content of $4.73 \%$ (termed "wet-bonding"). Three different epoxy resins are applied to study the bond performance of the CFRP-concrete interface when subjected to moisture ( $95 \%$ relative humidity). A total of 45 double-lap shear specimens were tested at the beginning of exposure and again after 1, 3, 6, and 12 months. All specimens with normal epoxy resins exhibited adhesive failure. The failure mode of specimens with hydrophobic epoxy resin changed from cohesive failure to mixed cohesive/adhesive failure and to adhesive failure according to the duration of exposure. Under moisture conditioning, the maximum shear stress $\left(\tau_{\max }\right)$ and corresponding slip $\left(s_{\max }\right)$ of the bond-slip curve first increased and then decreased or fluctuated over time. The same tendency was seen in the ultimate strain transmitted to the CFRP sheet, the interfacial fracture energy $\left(G_{f}\right)$, and the ultimate load $\left(P_{u}\right)$. Analytical models of $G_{f}$ and $P_{u}$ for the CFRP-concrete interface under moisture conditioning are presented.
\end{abstract}

\section{Introduction}

The use of fiber-reinforced polymer (FRP) composites has emerged as one of the most promising techniques in the field of concrete structural strengthening [1-4] due to their well-established advantages, which include a high strengthweight ratio, fatigue resistance, ease of installation, and costeffectiveness [5-9]. Of the various types of FRP composites, carbon fiber-reinforced polymer (CFRP) is used extensively for rehabilitation of concrete structures. It has shown outstanding performance when used for strengthening concrete structures, providing improvement of load carrying capacity, stiffness, or ductility. Although CFRP composites provide an effective method to strengthen concrete structures, the effectiveness of strengthening system mainly depends on the durability of adhesive bond between CFRP and concrete substrate [10-12].

In coastal regions such as southern China, Hong Kong, many concrete structures are wet at the time of repair and the CFRP-strengthened systems are subjected to moisture, under the influence of tides and wave-splashing. Therefore, the performance of CFRP in strengthening wet concrete should be well recognized for further application, and various methods have been studied. Zhou and Lucas [13] revealed that water sorption could modify the mechanical properties of epoxy resins. Tatar and Hamilton [14] reported that moisture had a negative effect on the adhesion properties of epoxy resin. Choi et al. [15] studied the CFRP bond capacity under hygrothermal exposure using a new three-point bend beam test. The results suggested that CFRP-concrete bond systems using different epoxies showed significant differences in durability, although the same type of fibers and the same type of concrete specimens were used. Tuakta and Büyüköztürk [16] conducted cyclic moisture conditioning tests and found that the adhesive bond cannot regain its original bond strength after successive wet-dry cycles at both room and high temperatures. Wan et al. [17] used modified double cantilever beam (MDCB) specimens to study the effects of water on 


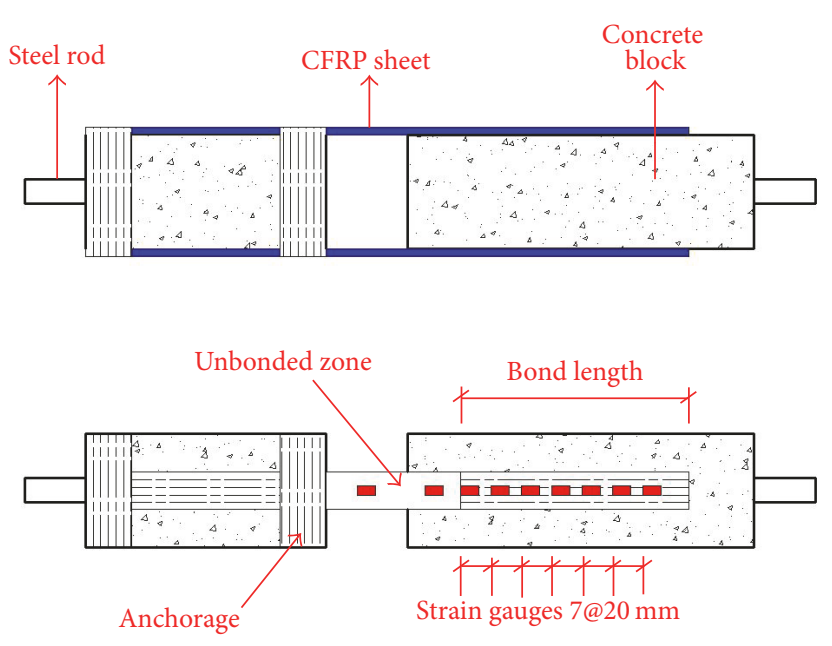

(a)

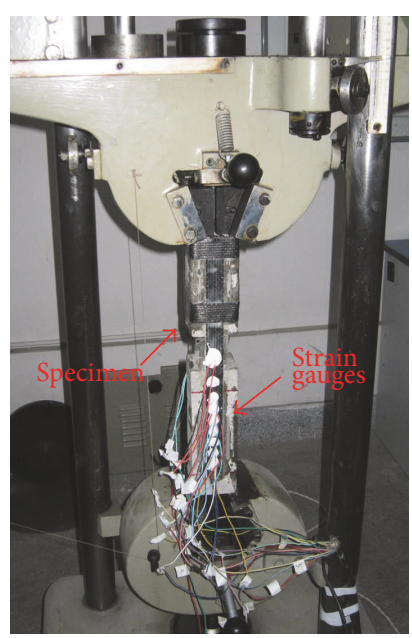

(b)

FIGURE 1: Test arrangement: (a) details of specimen; (b) photograph of test setup.

the CFRP-concrete bond during CFRP application and after CFRP curing. The results indicated that the presence of water during primer application caused a significant decrease in the bond quality. When a water-tolerant primer was applied, the bond strength increased, but it was not comparable to that of a dry-bonded specimen using the normal primer. The bond performance continued to degrade with exposure. The presence of water also changed the mode of failure from cohesive within the concrete to adhesive along the concrete-to-primer interface. Dai et al. [18] studied the effects of moisture on the initial and long-term bonding behavior of the CFRP-concrete interface using various primers and concluded that moisture strongly influenced the bond performance and that the application of an appropriate primer can eliminate the effects of concrete surface moisture on short-term interfacial bond performance. The failure mode changed from cohesive failure to interfacial failure, and the bond strength continued to degrade with moisture exposure. However, previous research studies have focused on the performance and duration of concrete members strengthened with conventional CFRP composites. Recently, a few studies have been conducted on the use of high modulus CFRP to strengthen concrete structures. Richardson [19] investigated the use of high modulus CFRP plate to strengthen damaged reinforced concrete beams. The results showed that the $400 \mathrm{GPa}$ CFRP of reinforcement ratio $0.17 \%$ increased the ultimate strength of concrete beam by up to $51 \%$ and enhanced flexural stiffness in the elastic and plastic ranges by $8 \%$ and $12 \%$. He also developed an analytical model to predict the performance of high modulus FRPstrengthened slender RC columns. Sadeghian and Fam [20] introduced a technique that aims at controlling second-order lateral deflection using longitudinal high modulus bonded reinforcement. Therefore it was encouraging to investigate the duration of high modulus CFRP-strengthened concrete structures.

This paper presents the experimental results from a series of high modulus CFRP-concrete double-lap specimens with the following purposes: (i) characterize the debonding process using mechanical parameters after moisture conditioning and (ii) provide reference for the establishment of relative strengthening codes. Three ambient-cured epoxy resins obtained from different suppliers, two conventional types (WSX [represented by A] and MA [represented by $\mathrm{B}]$ ) and a hydrophobic type (CH-3 [represented by $\mathrm{C}]$ ), are used in this study. Epoxy resin WSX is popularly used for dry concrete substrate and epoxy resin MA can be used for dry and wet concrete substrate, whereas epoxy resin $\mathrm{CH}-3$ is particularly formulated for use in wet, damp, or moist concrete substrates and is used to verify whether the hydrophobic epoxy resin can better cope with moisture at the CFRP-concrete interface over both short and long terms. Comparisons are presented on failure modes, bondslip relationships, interfacial fracture energy, and ultimate loads.

\section{Experimental Program}

2.1. Test Specimen. The 45 conditioned specimens were mechanically tested to failure in standard laboratory conditions. The duration of exposure to moisture was the only variable that was changed during the experiment. Because three different epoxy resins were used, these specimens were divided into three main groups. Each group was conditioned for 0 , $1,3,6$, and 12 months. All double-lap shear specimens are named in the form of RH-x-y-z. For example, RH-A-6-2 is specimen number 2 with epoxy resin A subjected to $95 \%$ relative humidity $(\mathrm{RH})$ for 6 months before testing.

2.2. Preparation of Specimen. Figure 1(a) shows a schematic view of the CFRP-concrete double-lap shear specimen. The $25 \mathrm{~mm}$ CFRP sheet is centered along the longitudinal axis of the $75 \mathrm{~mm}$ concrete block, leaving two $25 \mathrm{~mm}$ shoulders on the side of the bond to remove edge effects. The bond length is $150 \mathrm{~mm}$, and a $35 \mathrm{~mm}$ unbonded zone is left to avoid the loss of a concrete chunk by shearing near the loaded end 
TABLE 1: Material properties of CFRP coupon and epoxy resin.

\begin{tabular}{lcccc}
\hline Material & $\begin{array}{c}\text { Young's modulus } \\
(\mathrm{GPa})\end{array}$ & $\begin{array}{c}\text { Ultimate strength } \\
(\mathrm{MPa})\end{array}$ & $\begin{array}{c}\text { Shear strength } \\
(\mathrm{MPa})\end{array}$ & $\begin{array}{c}\text { Failure strain } \\
(\%)\end{array}$ \\
\hline CFRP & 245 & 3870 & - & 1.74 \\
CFRP-A & 266 & 3933 & - & 1.48 \\
CFRP-B & 268 & 3968 & - & 1.48 \\
CFRP-C & 292 & 4428 & 21 & 1.52 \\
Epoxy A & 2.4 & 33 & 22 & 1.40 \\
Epoxy B & 2.7 & 45 & 26 & 1.84 \\
Epoxy C & 4.5 & 48 & 1.65 \\
\hline
\end{tabular}

Note. CFRP-A: CFRP coupon using epoxy resin A; CFRP-B: CFRP coupon using epoxy resin B; CFRP-C: CFRP coupon using epoxy resin C.

$[21,22]$. The concrete blocks are cast using wooden molds, demolded after 24 hours, and cured for 28 days. Afterwards, all concrete blocks are submerged in salt water for 1 year so that the concrete's compressive strength remains stable during moisture exposure. The bonding sides of the concrete blocks are then sandblasted with a hand grinder to provide appropriate rough surfaces for bonding, and any debris, grease, laitance, and loose material at the surface are cleaned with acetone using a cotton cloth. To investigate the effects of the presence of water before bonding the CFRP sheets, the concrete substrate surfaces are preconditioned to simulate the construction conditions that may be encountered in a moist environment. All concrete blocks are submerged in deionized water for 3 days, removed, and wiped to measure the absorbed water. The difference in the weight of the concrete before and after conditioning represents the moisture mass uptake. In this process, the measured average moisture content of the concrete is $4.73 \%$. After measurement of moisture, the fully saturated CFRP sheet is carefully placed on the designed region of the concrete block upon which epoxy has been applied. A roller is used to squeeze out excessive epoxy until a uniform bonding layer is formed. In a similar manner, two $30 \mathrm{~mm}$-wide CFRP hoops with the fibers oriented in the transverse direction are wrapped to provide sufficient anchorage so that failure takes place at the bonded zone. All specimens are then cured in the laboratory for 1 week at ambient temperatures. It should be noted that, in the wetlayup system, epoxy resin is used to bond the CFRP sheet to concrete and at the same time serves as saturation resin for the CFRP sheet.

2.3. Moisture Conditioning. All specimens are conditioned at $20^{\circ} \mathrm{C} \pm 1^{\circ} \mathrm{C}$ and $95 \% \pm 3 \% \mathrm{RH}$ inside a conditioning chamber in a laboratory with moisture control. At each target exposure duration (i.e., 0, 1, 3, 6, and 12 months), three randomly chosen specimens for each epoxy resin are removed periodically for testing.

2.4. Material Properties. The concrete blocks are made from grade 42.5 Portland cement and aggregates with a maximum size of $15 \mathrm{~mm}$. The blocks are cast and cured following GB50010-2010 [23]. The average concrete cube strength after 1 year of immersion is $33.5 \mathrm{MPa}$, determined with three $150 \times 150 \times 150 \mathrm{~mm}$ concrete cubes. The CFRP sheet with a thickness of $0.167 \mathrm{~mm}$ is "NG" brand and supplied by Wuda Jucheng, a company in China. Table 1 presents its material properties according to the product data sheet. The properties of flat coupons made with different epoxy resins are determined from tensile tests in accordance with ASTM D3039 [24] and are shown in Table 1. CFRP coupons are made using the wet lay-up process. First, the CFRP sheets are brushed with mixed epoxy resin. Second, the CFRP sheets are cut into $15 \mathrm{~mm}$ wide $\times 250 \mathrm{~mm}$ long sections after 7-day curing at ambient temperature. Third, CFRP tabs and aluminum tabs are bonded at the two ends. Each coupon is tested using a universal testing machine at a speed of $1 \mathrm{~mm} / \mathrm{min}$, with a strain gauge adopted on the center. The three commercial two-part epoxy resins chosen for the current program, both as CFRP matrices and as adhesives, are (1) WSX epoxy resin (represented by A), (2) MA epoxy resin (represented by B), and (3) CH-3 epoxy resin (represented by $\mathrm{C}$ ). Table 1 summarizes their material properties according to the material data sheet supplied by their manufacturers.

2.5. Test Setup and Instrumentation. Before testing, all specimens are fitted with nine quarter-bridge strain gauges bonded to the CFRP's outer surface. Seven strain gauges in the bonded zone with a spacing of $20 \mathrm{~mm}$ are used to measure the strain distribution along the CFRP sheet at various loading levels, and the other two in the unbonded zone are used to record the tensile load. Strain measurement is recorded by an electronic acquisition system. The double-lap shear tests are carried out in standard laboratory conditions with a universal hydraulic testing machine (capacity of $100 \mathrm{kN}$ ) displacement controlled at $0.5 \mathrm{~mm} / \mathrm{min}$. After the specimen is rigidly clamped by steel rods at both ends, preliminary testing is conducted to carefully adjust the alignment of two symmetric CFPR sheets and clamps so the load can be transferred uniformly into the CFRP-concrete interface. The specimen is then tested individually in direct tension until the CFRP sheets are entirely pulled off (as shown in Figure 1). It should be noted that, for this double-lap specimen, the CFRP sheets of two sides would be peeled off in sequence. After one side is peeled off, the total load is suddenly applied eccentrically on the opposite side. Therefore, only the strain measurements of the first failure side are reported in this study. 


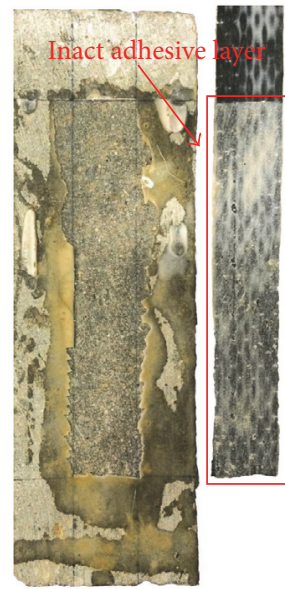

(a)

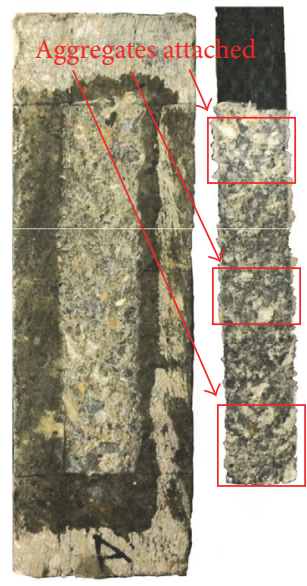

(b)

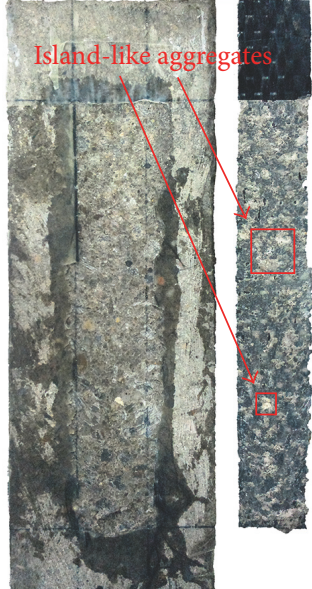

(c)

Figure 2: Typical failure modes: (a) adhesive failure; (b) cohesive failure; (c) mixed cohesive/adhesive failure.

\section{Experimental Results}

3.1. Failure Mode. Three predominant failure modes were observed: adhesive failure, cohesive failure, and mixed cohesive/adhesive failure. Adhesive failure occurs between the epoxy and the concrete substrate, with or without loose concrete remaining on the CFRP sheet. Cohesive failure occurs inside the concrete block near the epoxy-concrete contact surface, and many particles of coarse and fine aggregate are attached to the surface that failed. Mixed cohesive/adhesive failure is a combination of cohesive failure and adhesive failure. Table 2 summarizes the failure modes of all specimens, and Figure 2 presents selected images of failed specimens (the left part shows substrates after peeling, and the right part shows peeled CFRP sheets).

When the concrete substrates are wet, specimens $\mathrm{RH}-$ A- $-0-z$ and $\mathrm{RH}-\mathrm{B}-0-z$ are representative of adhesive failure (Figure 2(a)). The peeled part consists of the CFRP sheet and an almost-intact adhesive layer without adhering aggregates. This failure mode differs from that observed in other studies when concrete is dry $[25,26]$, which indicates that the initial wet concrete substrate has a negative effect on the bond between epoxy resin and concrete because the hydrogen bonds between the epoxy and the concrete substrate may be disturbed by the presence of water molecules at the interface [27]. With the increase in moisture exposure, all series RH-A- $y-z$ and RH-B $-y-z$ specimens show adhesive failure. This means that the effectiveness of mechanical bond was weakened. And it can be contributed to the residual water within concrete surface and the degradation properties of epoxy resins $[28,29]$.

In contrast, most samples with hydrophobic epoxy specimens exhibit various degrees of cohesive failure (Figure 2(b)). The failure begins near the loaded end and then cracks kinks into the concrete substrate and propagates parallel to the interface until CFRP sheets are pulled off. Many aggregates are attached to the CFRP sheet. Nevertheless, after 3 months of exposure, one conditioned specimen displays a mixed cohesive/adhesive failure in the concrete, with a relatively small amount of island-like residual aggregates remaining (Figure 2(c)). Fewer aggregates are attached on the CFRP sheet as the duration of exposure increases. When conditioning up to 12 months, the failure of specimen $\mathrm{RH}-\mathrm{C}$ 12 is characteristic of adhesive failure. The negligible amount of mortar or fine aggregate bonded on the CFRP sheet is indicative of the poor bond between the epoxy and the concrete. This result indicates that, after long exposures, moisture could greatly influence the durability of the epoxy-concrete interface. The failure shift is thought to be due to (i) the possibility of resin degradation because of moisture reaction or chain scission and (ii) the reduction of interface bonding caused by water presence via water absorption or moisture diffusion. Therefore, for long exposures, this deterioration renders the epoxy-concrete interface the weakest link of the CFRP-strengthened system, resulting in adhesive failure between the epoxy and the concrete.

3.2. Bond-Slip Relationship. Based on the linear elastic assumption and Hook's law, the average bond shear stress between two adjacent strain gauges $\left(\tau_{\mathrm{av}}\right)$ can be obtained via strain measurement along the CFRP sheet by the following equation:

$$
\tau_{\mathrm{av}}=\frac{E_{f} t_{f}\left(\varepsilon_{i}-\varepsilon_{i-1}\right)}{\Delta x} \quad i \in(2, \ldots, 7)
$$

where $E_{f}$ and $t_{f}$ are the elastic modulus and thickness of the CFRP sheet and $\varepsilon_{i}-\varepsilon_{i-1}$ is the axial strain difference between adjacent CFRP strains at locations $i$ and $i-1$, which are separated by a distance $\Delta x$.

Neglecting the concrete strain, the relative slip $\left(s_{i}\right)$ at gauge location $i$ can be written as

$$
s_{i}=\frac{\Delta x}{2}\left(\varepsilon_{1}+2 \sum_{j=2}^{i-1} \varepsilon_{j}+\varepsilon_{i}\right) \quad i \in(2, \ldots, 7)
$$


TABLE 2: Test results of all specimens.

\begin{tabular}{|c|c|c|c|c|c|c|c|c|c|c|}
\hline $\begin{array}{l}\text { Specimen } \\
\text { ID }\end{array}$ & $\begin{array}{c}\text { Exposure } \\
\text { (month) }\end{array}$ & $\begin{array}{c}\tau_{\max } \\
(\mathrm{MPa})\end{array}$ & $\begin{array}{c}\text { Average } \\
\tau_{\max }\end{array}$ & $\begin{array}{l}S_{\max } \\
(\mathrm{mm})\end{array}$ & $\begin{array}{c}\text { Average } \\
S_{\max }\end{array}$ & $\begin{array}{c}G_{f} \\
(\mathrm{~N} \cdot \mathrm{mm} / \mathrm{mm} 2)\end{array}$ & $\begin{array}{c}\text { Average } \\
G_{f}\end{array}$ & $\begin{array}{c}P_{u} \\
(\mathrm{kN})\end{array}$ & $\begin{array}{c}\text { Average } \\
P_{u}\end{array}$ & $\begin{array}{c}\text { Failure } \\
\text { mode }\end{array}$ \\
\hline RH-A-0-1 & & 5.464 & & 0.034 & & 0.229 & & 3.619 & & $\mathrm{AD}$ \\
\hline RH-A-0-2 & 0 & 5.875 & 5.670 & 0.041 & 0.038 & 0.348 & 0.277 & 4.508 & 4.364 & $\mathrm{AD}$ \\
\hline RH-A-0-3 & & 5.670 & & 0.039 & & 0.254 & & 4.964 & & $\mathrm{AD}$ \\
\hline RH-A-1-1 & & 7.422 & & 0.057 & & 0.625 & & 5.255 & & $\mathrm{AD}$ \\
\hline RH-A-1-2 & 1 & 6.337 & 6.021 & 0.033 & 0.043 & 0.375 & 0.406 & 4.462 & 4.786 & $\mathrm{AD}$ \\
\hline RH-A-1-3 & & 4.304 & & 0.038 & & 0.219 & & 4.641 & & $\mathrm{AD}$ \\
\hline RH-A-3-1 & & 4.999 & & 0.066 & & 0.363 & & 3.931 & & $\mathrm{AD}$ \\
\hline RH-A-3-2 & 3 & 7.475 & 6.036 & 0.048 & 0.051 & 0.493 & 0.395 & 4.657 & 4.468 & $\mathrm{AD}$ \\
\hline RH-A-3-3 & & 5.636 & & 0.037 & & 0.328 & & 4.817 & & $\mathrm{AD}$ \\
\hline RH-A-6-1 & & 4.640 & & 0.045 & & 0.262 & & 3.639 & & $\mathrm{AD}$ \\
\hline RH-A-6-2 & 6 & 5.709 & 5.103 & 0.040 & 0.038 & 0.320 & 0.274 & 4.324 & 4.023 & $\mathrm{AD}$ \\
\hline RH-A-6-3 & & 4.960 & & 0.027 & & 0.240 & & 4.105 & & $\mathrm{AD}$ \\
\hline RH-A-12-1 & & 5.057 & & 0.039 & & 0.253 & & 3.887 & & $\mathrm{AD}$ \\
\hline RH-A-12-2 & 12 & 3.315 & 4.192 & 0.036 & 0.035 & 0.164 & 0.206 & 4.311 & 3.898 & $\mathrm{AD}$ \\
\hline RH-A-12-3 & & 4.204 & & 0.031 & & 0.200 & & 3.497 & & $\mathrm{AD}$ \\
\hline RH-B-0-1 & & 5.521 & & 0.039 & & 0.252 & & 3.820 & & $\mathrm{AD}$ \\
\hline RH-B-0-2 & 0 & 6.179 & 5.685 & 0.041 & 0.042 & 0.324 & 0.287 & 4.587 & 4.179 & $\mathrm{AD}$ \\
\hline RH-B-0-3 & & 5.355 & & 0.044 & & 0.285 & & 4.130 & & $\mathrm{AD}$ \\
\hline RH-B-1-1 & & 5.215 & & 0.049 & & 0.404 & & 4.666 & & $\mathrm{AD}$ \\
\hline RH-B-1-2 & 1 & 5.649 & 5.491 & 0.038 & 0.043 & 0.336 & 0.350 & 4.111 & 4.453 & $\mathrm{AD}$ \\
\hline RH-B-1-3 & & 5.609 & & 0.041 & & 0.311 & & 4.582 & & $\mathrm{AD}$ \\
\hline RH-B-3-1 & & 6.144 & & 0.039 & & 0.397 & & 4.734 & & $\mathrm{AD}$ \\
\hline RH-B-3-2 & 3 & 5.708 & 6.249 & 0.036 & 0.040 & 0.267 & 0.376 & 4.417 & 4.667 & $\mathrm{AD}$ \\
\hline RH-B-3-3 & & 6.894 & & 0.044 & & 0.463 & & 4.850 & & $\mathrm{AD}$ \\
\hline RH-B-6-1 & & 5.084 & & 0.052 & & 0.366 & & 4.671 & & $\mathrm{AD}$ \\
\hline RH-B-6-2 & 6 & 4.913 & 5.598 & 0.035 & 0.046 & 0.286 & 0.365 & 4.451 & 4.590 & $\mathrm{AD}$ \\
\hline RH-B-6-3 & & 6.797 & & 0.051 & & 0.443 & & 4.649 & & $\mathrm{AD}$ \\
\hline RH-B-12-1 & & 3.560 & & 0.036 & & 0.224 & & 4.127 & & $\mathrm{AD}$ \\
\hline RH-B-12-2 & 12 & 5.478 & 4.519 & 0.037 & 0.037 & 0.263 & 0.243 & 4.141 & 4.134 & $\mathrm{AD}$ \\
\hline RH-B-12-3 & & - & & & & - & & - & & $\mathrm{AD}$ \\
\hline RH-C-0-1 & & 7.819 & & 0.048 & & 0.499 & & 5.307 & & $\mathrm{CO}$ \\
\hline $\mathrm{RH}-\mathrm{C}-0-2$ & 0 & 9.841 & 8.842 & 0.053 & 0.050 & 0.710 & 0.572 & 6.532 & 5.662 & $\mathrm{CO}$ \\
\hline RH-C-0-3 & & 8.865 & & 0.050 & & 0.507 & & 5.146 & & $\mathrm{CO}$ \\
\hline RH-C-1-1 & & 8.172 & & 0.056 & & 0.850 & & 7.148 & & $\mathrm{CO}$ \\
\hline RH-C-1-2 & 1 & 10.495 & 9.600 & 0.056 & 0.058 & 0.864 & 0.887 & 6.562 & 6.725 & $\mathrm{CO}$ \\
\hline RH-C-1-3 & & 10.132 & & 0.062 & & 0.948 & & 6.464 & & $\mathrm{CO}$ \\
\hline RH-C-3-1 & & 8.067 & & 0.057 & & 0.517 & & 5.345 & & $\mathrm{CO}$ \\
\hline RH-C-3-2 & 3 & 5.895 & 7.163 & 0.049 & 0.063 & 0.368 & 0.554 & 4.997 & 5.747 & $\mathrm{C} / \mathrm{A}$ \\
\hline $\mathrm{RH}-\mathrm{C}-3-3$ & & 7.528 & & 0.082 & & 0.776 & & 6.900 & & $\mathrm{CO}$ \\
\hline RH-C-6-1 & & 5.868 & & 0.051 & & 0.563 & & 5.941 & & $\mathrm{AD}$ \\
\hline RH-C-6-2 & 6 & 7.778 & 7.492 & 0.088 & 0.064 & 0.671 & 0.611 & 6.145 & 6.212 & $\mathrm{C} / \mathrm{A}$ \\
\hline RH-C-6-3 & & 8.830 & & 0.054 & & 0.597 & & 6.551 & & $\mathrm{C} / \mathrm{A}$ \\
\hline RH-C-12-1 & & 9.332 & & 0.050 & & 0.471 & & 5.601 & & $\mathrm{AD}$ \\
\hline $\mathrm{RH}-\mathrm{C}-12-2$ & 12 & - & 8.182 & - & 0.051 & - & 0.487 & - & 5.586 & $\mathrm{AD}$ \\
\hline RH-C-12-3 & & 7.032 & & 0.052 & & 0.504 & & 5.571 & & $\mathrm{AD}$ \\
\hline
\end{tabular}

Note. AD: adhesive failure; CO: cohesive failure; C/A: mixed cohesive/adhesive failure. 

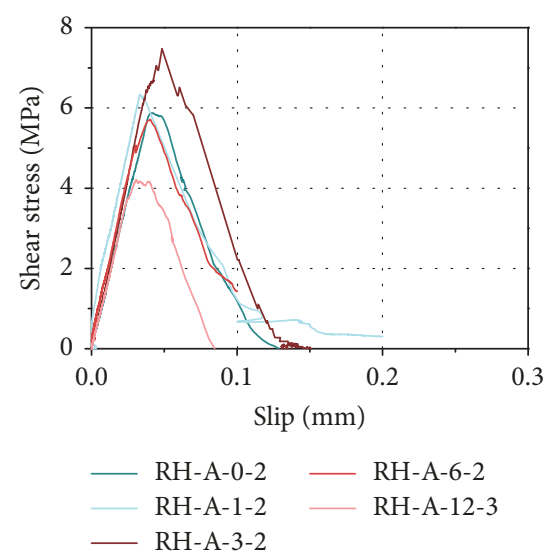

(a)
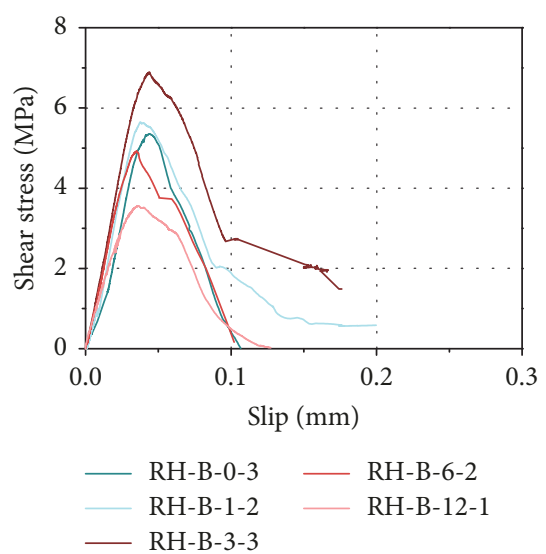

(b)
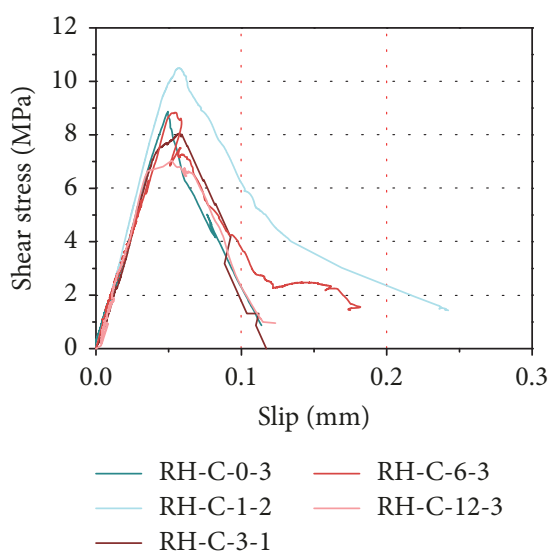

(c)

FIGURE 3: Representative bond-slip curves at the loaded end: (a) RH-A- $y-z$ specimens; (b) RH-B- $y-z$ specimens; (c) RH-C- $y-z$ specimens.

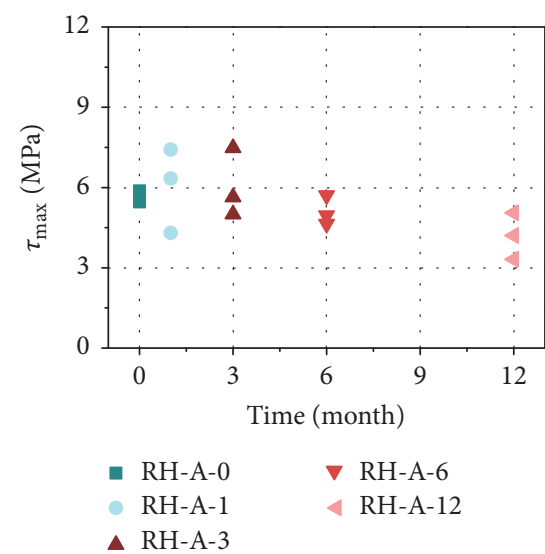

(a)

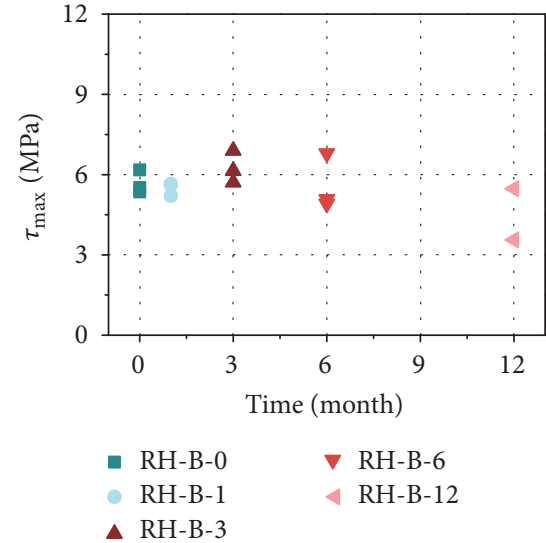

(b)

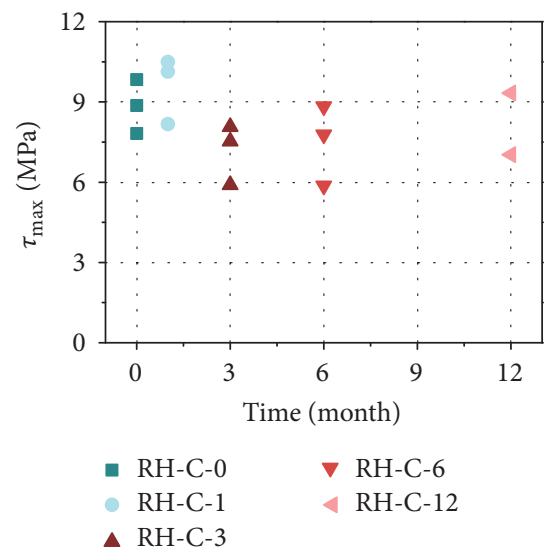

(c)

FIgURE 4: Comparison of $\tau_{\max }$ for specimens: (a) RH-A- $y$ - $z$ specimens; (b) RH-B- $y-z$ specimens; (c) RH-C- $y$ - $z$ specimens.

where $\varepsilon_{1}$ is the strain at the free end of the CFRP sheet; $\varepsilon_{j}$ is the strain of $j$ th gauge attached to the CFRP sheet; and $\varepsilon_{i}$ is the strain at the loaded end of the CFRP sheet. Combining (1) and (2) yields the $\tau$-s curve along the CFRP-concrete interface.

Plotting all of the curves in one figure may result in overlapping, so it is difficult to characterize the effects of moisture. For simplicity, therefore, only one representative curve for specimens at each target exposure time is presented in Figure 3, in which all $\tau$-s curves exhibit a bilinear shape. It is found that the exposure has little effect on the initial stiffness of the upward section, but it significantly influences the maximum shear stress $\left(\tau_{\max }\right)$, the corresponding slip $\left(s_{\max }\right)$, and the area under the curve. To characterize the effects of moisture exposure, all values of $\tau_{\max }$ and $s_{\max }$ are plotted in Figures 4 and 5, respectively. For the RH-A$y-z$ specimens, a synchronous change of $\tau_{\max }$ and $s_{\max }$ is observed, increasing in the first 3 months and decreasing with longer exposure. For the RH-B- $y-z$ specimens, after a slight inverse variation at 1 month of exposure, $\tau_{\max }$ and $s_{\max }$ increase at 3 months and then decrease gradually. For the RH-C- $y$ - $z$ specimens, $\tau_{\max }$ reaches a maximum at 1 month of exposure and then fluctuates over time, whereas $s_{\max }$ shows progressive growth up to 6 months with a final drop at 12 months. The values increase in the first few months because the postcuring effect of adhesive layer enhances the interfacial bonding even in a moist environment. However, due to the different properties of these three epoxy resins, the highest $\tau_{\max }$ and $s_{\max }$ values are achieved after different exposure durations, because the mechanical properties of CFRP sheet remain almost unaffected under accelerated conditioning $[30,31]$ and the concrete compressive strength is almost unchanged. One possible reason for the decreasing trend is that the absorbed water, acting as a plasticizer, usually reduces both mechanical and adhesion properties of epoxy resin during conditioning [17]. This phenomenon would increase the porosity and flaws within the epoxy resin, which in turn would have a detrimental effect on the interfacial shear strength.

Figure 6 compares the CFRP strain distribution along the bond length with some representative examples. In general, all specimens behave similarly, showing a more or less exponential trend in the strain distribution profile. The strain initially transfers within $20 \mathrm{~mm}$ of the loaded end and then transfers towards the free end. Generally, the strain of the 


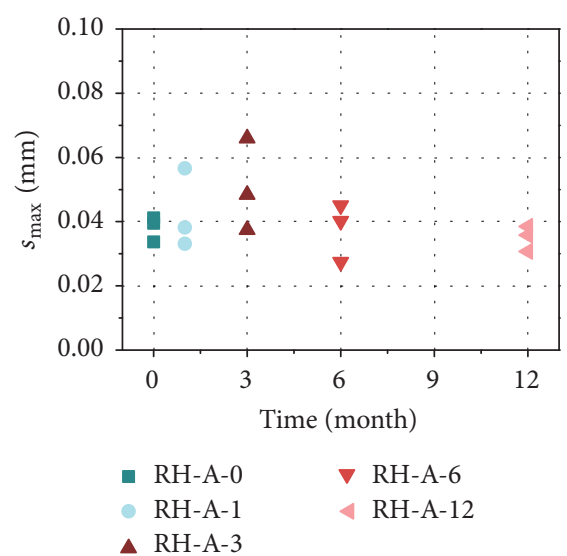

(a)

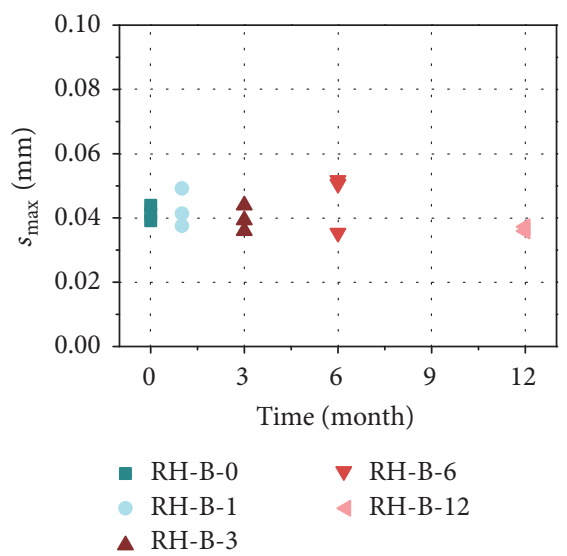

(b)

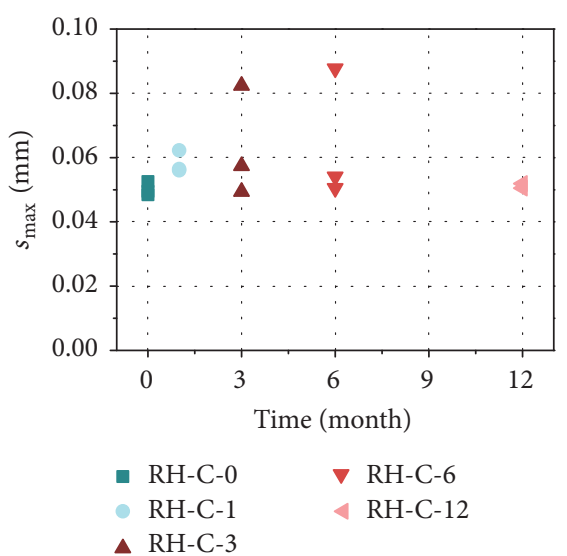

(c)

FIGURE 5: Comparison of $s_{\max }$ for specimens: (a) RH-A- $y-z$ specimens; (b) RH-B- $y-z$ specimens; (c) RH-C- $y-z$ specimens.

CFRP sheet decreases with an increase in the distance from the loaded end.

With the increase in the applied load, the longitudinal strain of the CFRP sheet increases. However, when the applied load reaches the failure load, the ultimate strain of the CFRP sheet is lower than $6000 \mu \varepsilon$, which is less than half of the elongation of CFRP sheet. This means that the tensile capacity of the CFRP sheet in the CFRP-to-concrete joint cannot be fully used.

With the increase in the exposure time, almost all the longitudinal strains of the CFRP sheet beyond $80 \mathrm{~mm}$ from the loaded end are very limited, implying that the exposure time on the transfer length is limited. However, the specimens' ultimate strains show various trends. The ultimate strain of specimens RH-A- $y-z$ achieves the highest value at 1 month and then decreases over time. The ultimate strain of specimens RH-B- $y-z$ reaches the maximum at 3 months and then drops. The ultimate strain of RH-C- $y-z$ fluctuates within a range of $3500 \mu \varepsilon$ to $5500 \mu \varepsilon$ and does not show the trend of monotonic change.

3.3. Interfacial Fracture Energy. Figure 7 presents the values of interfacial fracture energy $\left(G_{f}\right)$ in a moist environment. For RH-A- $y-z$ specimens, $G_{f}$ increases rapidly in the first month and remains almost unchanged until 3 months and then decreases sharply over time. For RH-B- $y-z$ specimens, $G_{f}$ increases until 6 months and then decreases. For RH-C- $y$ $z$ specimens, $G_{f}$ peaks at 1 month, and the general trend over the next few months is decreasing-increasing-decreasing. With respect to the maximum value of $G_{f},+31.77 \%, 0.00 \%$, $-2.71 \%,-32.51 \%$, and $-49.26 \%$ variation for RH-A- $y-z$ specimens; $+23.67 \%,+6.91 \%,+0.00 \%,-2.93 \%$, and $-35.37 \%$ variation for RH-B- $y-z$ specimens; and $+35.51 \%, 0.00 \%,-37.54 \%$, $-31.12 \%$, and $-45.10 \%$ variation for $\mathrm{RH}-\mathrm{C}-y-z$ specimens are observed. This phenomenon could be explained by (i) the solidification of epoxy resins in the first few months and (ii) the reduction of the mechanical and adhesion properties of epoxy resin caused by water infiltration and diffusion through microcracks and voids with longer exposure. According to the variation trend shown in Figure 7, a Gaussian function that relates the interfacial fracture energy after conditioning $\left(G_{f \text {,moisture }}\right)$ to the exposure time ( $t$, months) is obtained by curve fitting:

$$
G_{f, \text { moisture }}=\left(A+\frac{B}{C \sqrt{\pi / 2}} e^{-2\left(\left(t-t_{c}\right)^{2} / C^{2}\right)}\right) G_{f},
$$

where $A$ is the residual factor, $B$ and $C$ are constants, $t_{c}$ is the time when the highest fracture energy is attained, and $G_{f}$ is the interfacial fracture energy of the 0 -month specimens. For the RH-A- $y-z$ specimens, $A, B, C$, and $t_{c}$ achieved by regression analysis are $0.84,2.70,3.37$, and 3.19 , respectively. For the RH-B- $y-z$ specimens, $A, B, C$, and $t_{c}$ are $0.83,3.81$, 5.78 , and 4.24 , respectively. For the RH-C- $y-z$ specimens, $A$, $B, C$, and $t_{c}$ are $0.85,3.23,4.32$, and 2.56 , respectively.

3.4. Ultimate Load. Figure 8 shows the values of the ultimate load $\left(P_{u}\right)$ under moisture conditioning. The average $P_{u}$ of the RH-A- $y-z$ specimens increases in the first month and then decreases progressively. The average values of $\mathrm{RH}-\mathrm{A}$ $0-z(4.364 \mathrm{kN}), \mathrm{RH}-\mathrm{A}-3-z(4.468 \mathrm{kN}), \mathrm{RH}-\mathrm{A}-6-z(4.023 \mathrm{kN})$, and $\mathrm{RH}-\mathrm{A}-12-z(3.898 \mathrm{kN})$ vary by $+8.82 \%,-6.64 \%,-15.94 \%$, and $-18.55 \%$, respectively, from that of RH-A-1- $z(4.786 \mathrm{kN})$. For the RH-B- $y-z$ specimens, the $P_{u}$ values show similar variation, and the maximum value occurs at 3 months $(4.677 \mathrm{kN})$. With the duration of exposure, $P_{u}$ of $\mathrm{RH}$ B-6- $z(4.590 \mathrm{kN})$ and RH-B-12- $z(4.134 \mathrm{kN})$ decrease by $1.65 \%$ and $11.42 \%$, respectively. For the RH-C- $y-z$ specimens, cohesive failure inside the concrete substrate results in the highest $P_{u}$. However, $P_{u}$ shows a different trend, attaining its maximum value after 1 month and then fluctuating over time. The decrease in strength is associated with a change in the failure mode from cohesive failure to mixed cohesive/adhesive failure or adhesive failure. When the duration of exposure reaches 12 months, about $16.94 \%$ loss of the ultimate load associated with adhesive failure is observed. 


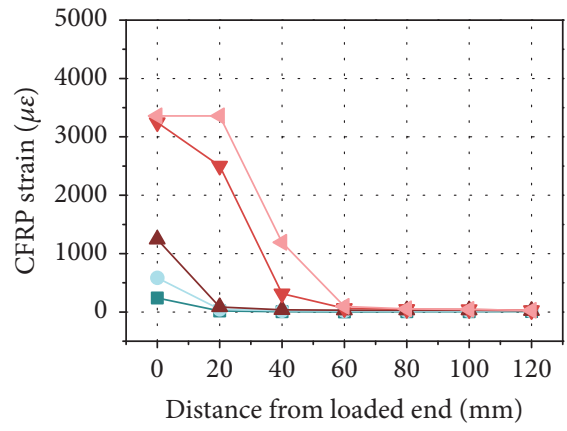

$\rightarrow-1 \mathrm{kN}$

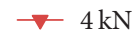

$-2 \mathrm{kN}$

$-4.508 \mathrm{kN}$

(a1)

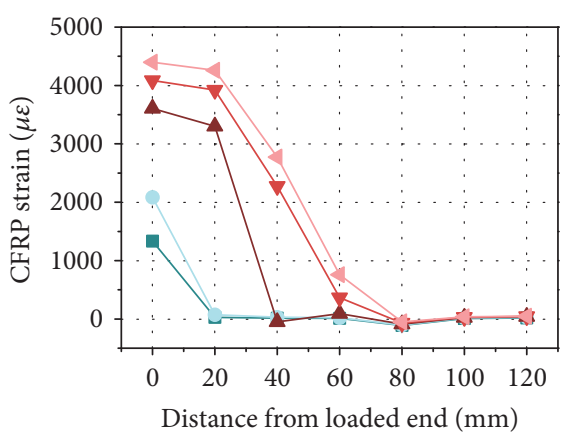

$-1 \mathrm{kN}$

$\rightarrow-4 \mathrm{kN}$

$-2 \mathrm{kN}$

$-4.462 \mathrm{kN}$

(a2)

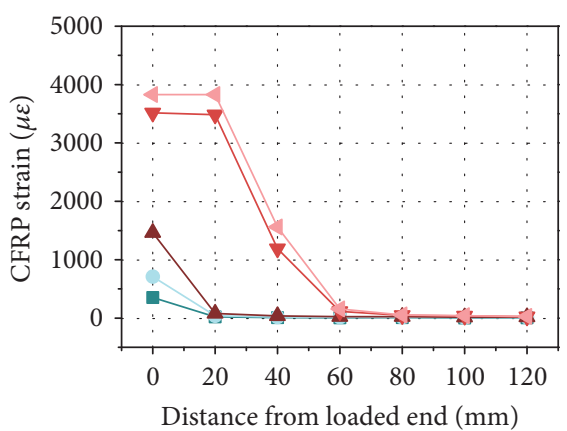

$-1 \mathrm{kN}$

$\rightarrow-4 \mathrm{kN}$

$-2 \mathrm{kN}$

$-4.657 \mathrm{kN}$

(a3)

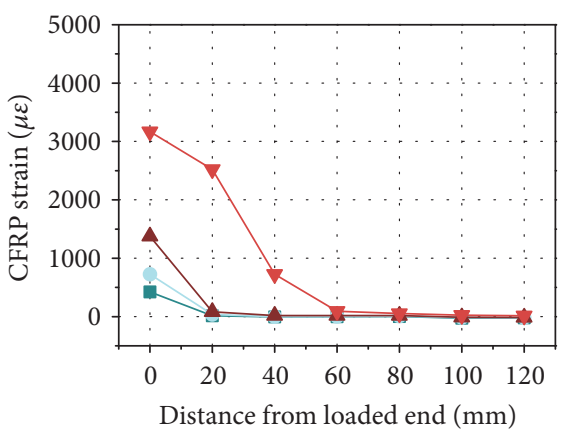

$\begin{array}{ll}-1 \mathrm{kN} & -3 \mathrm{kN} \\ -2 \mathrm{kN} & \rightarrow-4.324 \mathrm{kN}\end{array}$

(a4)
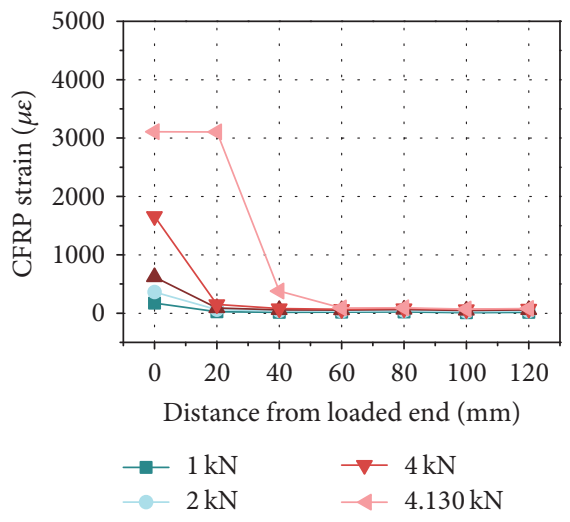

(b1)

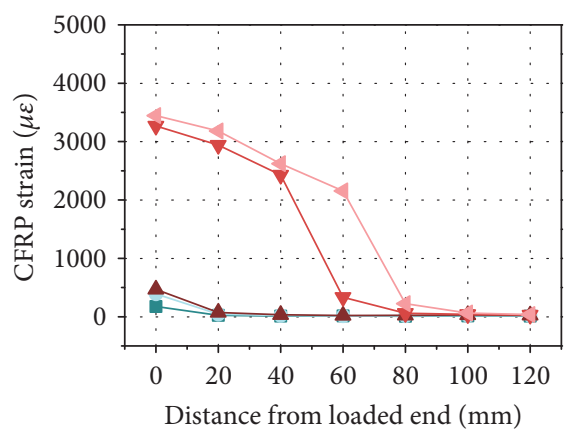

$-1 \mathrm{kN}$

$\rightarrow \quad 4 \mathrm{kN}$

- $2 \mathrm{kN}$

$-4.111 \mathrm{kN}$

(b2)

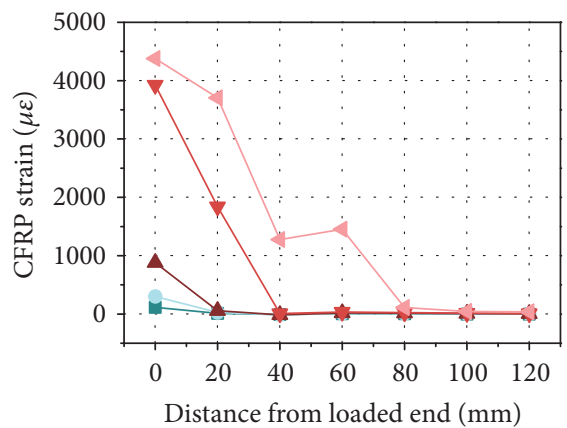

$-1 \mathrm{kN}$

$-2 \mathrm{kN}$

$\neg-4 \mathrm{kN}$

$-4.850 \mathrm{kN}$

(b3)

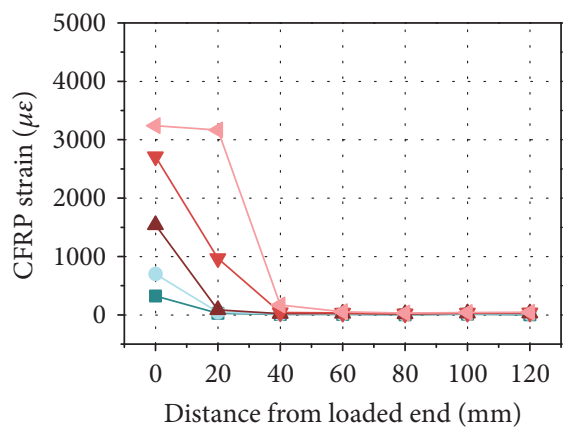

$-1 \mathrm{kN}$

$\rightarrow-4 \mathrm{kN}$

$-2 \mathrm{kN}$

$-4.451 \mathrm{kN}$

(b4)
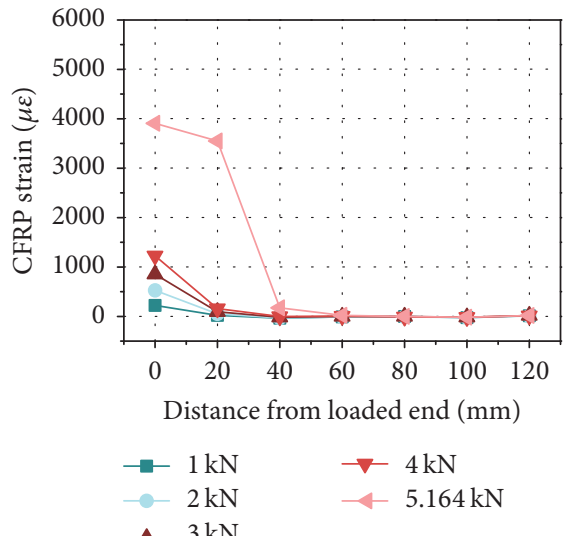

(c1)

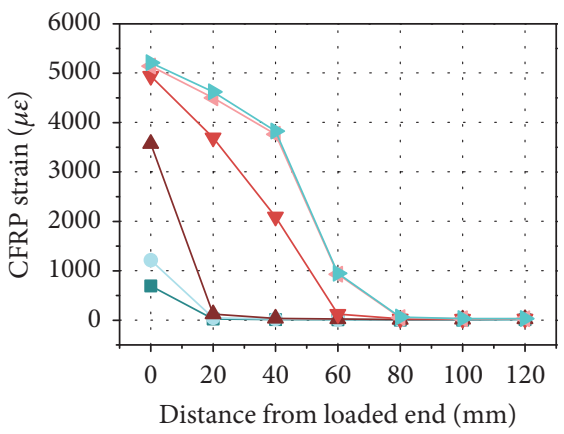

$-1 \mathrm{kN}$

- $2 \mathrm{kN}$

$\rightarrow-4 \mathrm{kN}$

$-3 \mathrm{kN}$

(c2)

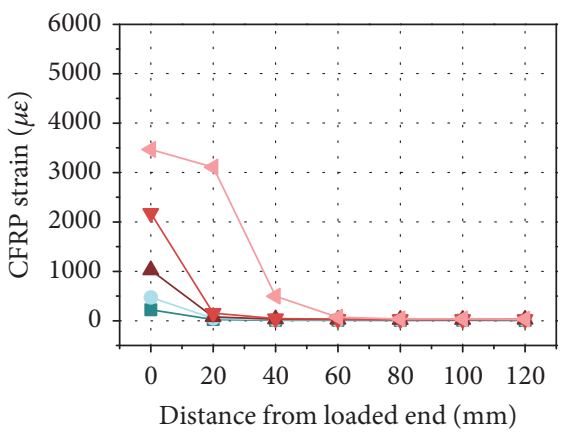

$-1 \mathrm{kN}$

$\neg-4 \mathrm{kN}$

$-2 \mathrm{kN}$

$-5.345 \mathrm{kN}$

$-3 \mathrm{kN}$

(c3)

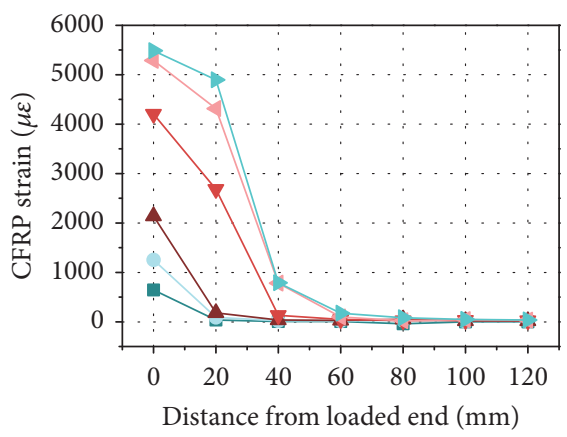

$-1 \mathrm{kN}$
$-2 \mathrm{kN}$
$-3 \mathrm{kN}$

$\rightarrow 4 \mathrm{kN}$

$-5 \mathrm{kN}$

(c4)

Figure 6: Continued. 


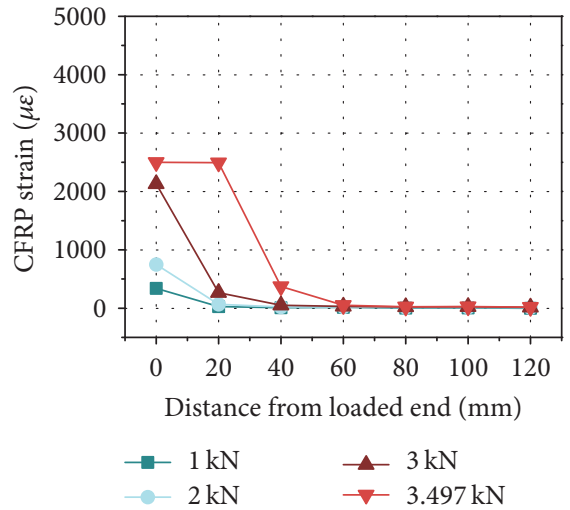

(a5)

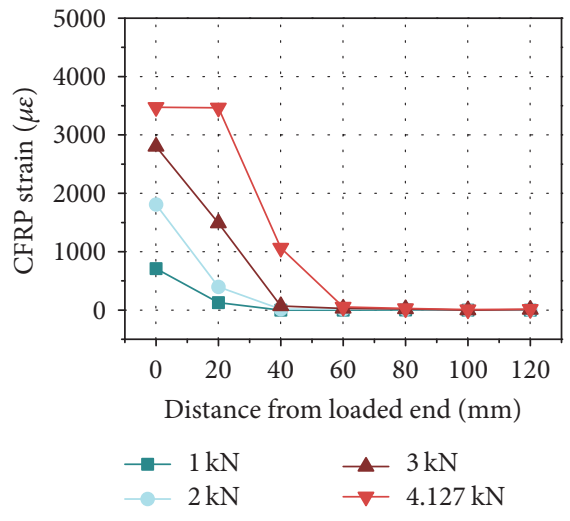

(b5)

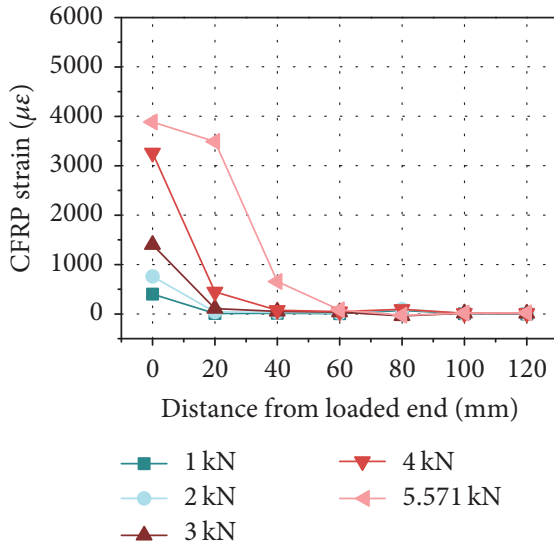

(c5)

FiguRE 6: Representative CFRP strain distribution along the bonded length: (a1) RH-A-0-2; (b1) RH-B-0-3; (c1) RH-C-0-3; (a2) RH-A-1-2; (b2) RH-B-1-2; (c2) RH-C-1-2; (a3) RH-A-3-2; (b3) RH-B-3-1; (c3) RH-C-3-1; (a4) RH-A-6-3; (b4) RH-B-6-2; (c4) RH-C-6-3; (a5) RH-A-12-1; (b5) RH-B-12-1; (c5) RH-C-12-3.

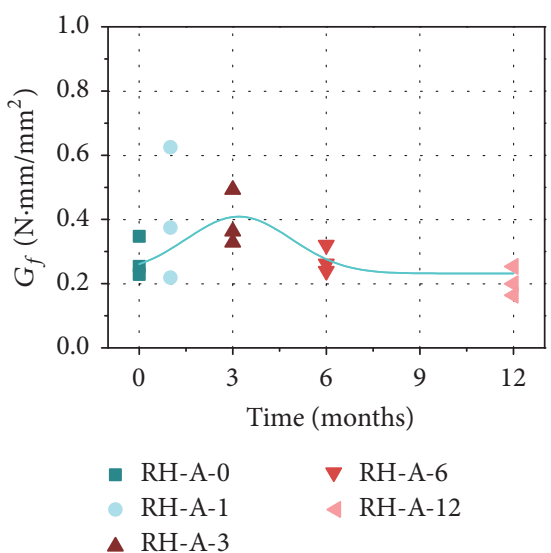

(a)

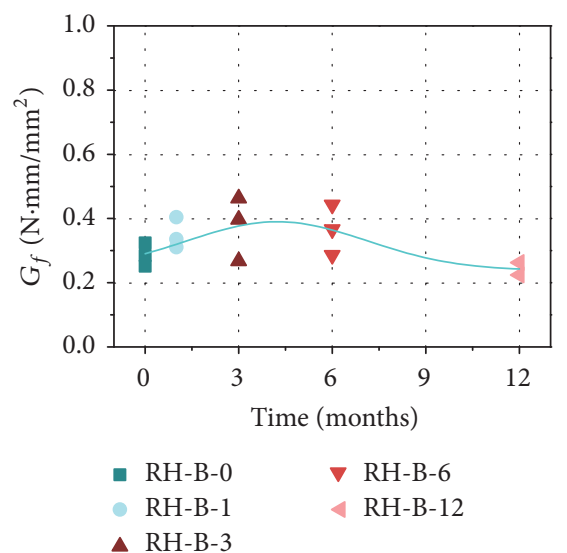

(b)

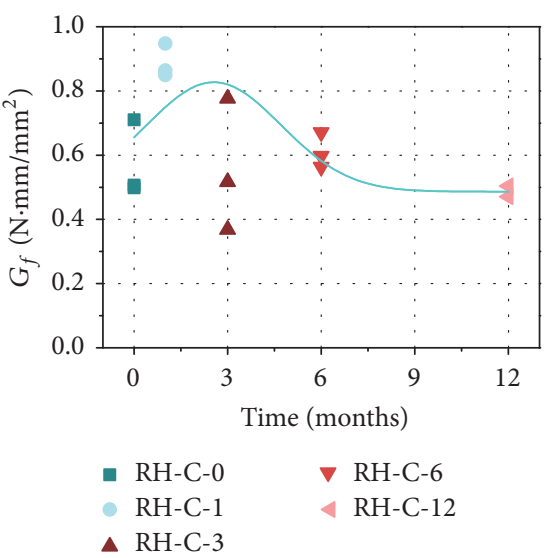

(c)

FIGURE 7: Comparison of Gf for specimens: (a) RH-A- $y$ - $z$ specimens; (b) RH-B- $y-z$ specimens; (c) RH-C- $y$ - $z$ specimens.
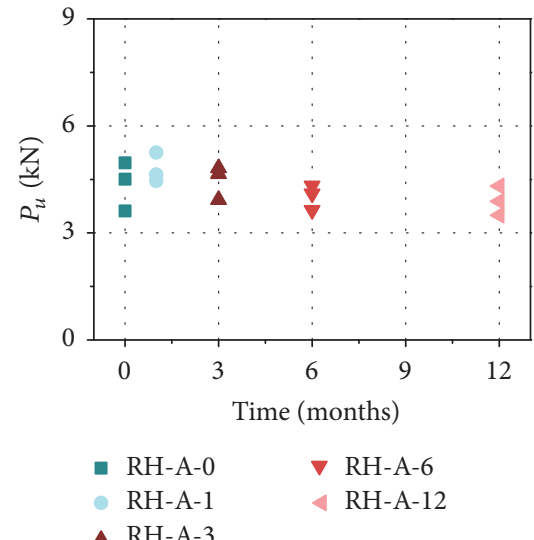

$\Delta \mathrm{RH}-\mathrm{A}-3$

(a)

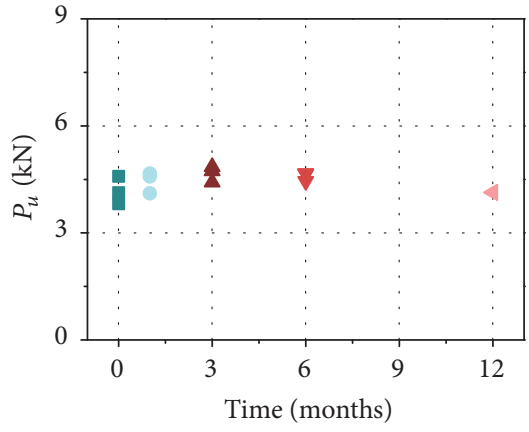

- $\mathrm{RH}-\mathrm{B}-0$

- RH-B-1

RH-B-3

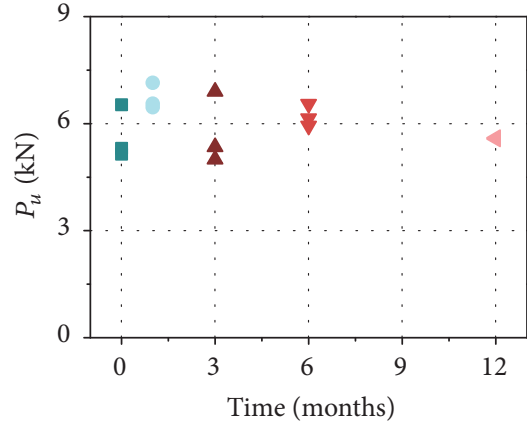

- $\mathrm{RH}-\mathrm{C}-\mathrm{O}$

$\checkmark$ RH-C-6

- $\mathrm{RH}-\mathrm{C}-1$

- $\mathrm{RH}-\mathrm{C}-3$

(c)

FIGURE 8: Comparison of $P_{u}$ for specimens: (a) RH-A- $y$ - $z$ specimens; (b) RH-B- $y-z$ specimens; (c) RH-C- $y$ - $z$ specimens. 


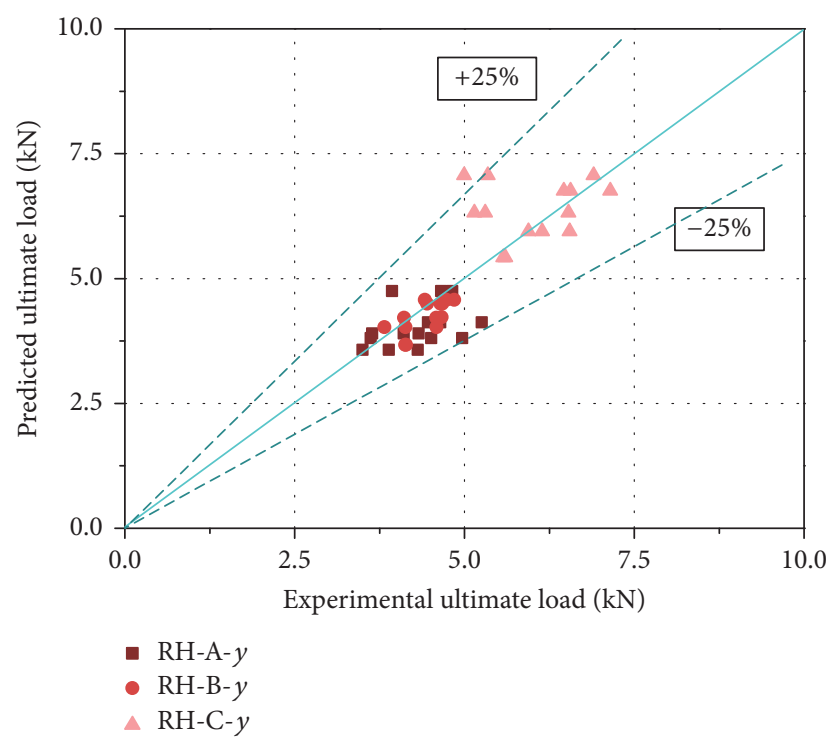

Figure 9: Comparison of $P_{u}$ between prediction and experiments.

This phenomenon could be explained by the relationship between $P_{u}$ and $G_{f}$. According to mode in $[32,33]$, the ultimate load is given by

$$
P_{u}=b_{f} \sqrt{2 E_{f} t_{f} G_{f}} .
$$

Because $E_{f}$ of the CFRP sheet is nearly unchanged after moisture conditioning in this study (as well as $t_{f}$ and $b_{f}$ ), the variation of $P_{u}$ is similar to that of $G_{f}$, as discussed in Section 3.3.

Figure 9 plots a comparison of the ultimate load determined by (4) and the average value obtained experimentally for each exposure duration. The results demonstrate satisfactory agreement, with deviations of less than $25 \%$.

\section{Conclusions}

An experimental study was conducted with 45 wet-bonded specimens fabricated by three different epoxy resins to investigate the effects of moisture on the initial and long-term interface behavior. The following conclusions are reached within the scope of this study.

(1) All RH-A- $y-z$ and RH-B- $y-z$ specimens exhibited an adhesive failure mode, but, for RH-C- $y-z$ specimens, the failure mode was obviously affected by moisture exposure. It likely changed over time from cohesive failure to mixed cohesive/adhesive failure and to adhesive failure.

(2) A bond-slip relationship was obtained from strain reading. The CFRP-concrete interface under moisture conditioning increased during the first few months and then decreased or fluctuated over time in terms of $\tau_{\max }$ and $s_{\max }$.

(3) Moisture exposure tended to increase the ultimate strain of specimens initially, followed by a progressive decrease or fluctuation.
(4) The interfacial fracture energy increased first and then decreased gradually or fluctuated over time. The ultimate load exhibited a similar trend of variation. Models are proposed to predict the interfacial fracture energy and ultimate load for specimens.

\section{Conflicts of Interest}

The authors declare that there are no conflicts of interest.

\section{Acknowledgments}

The tests reported herein were made possible by the financial support from the National Natural Science Foundation of China (51578428) and Special Project on Technical Innovation of Hubei (no. 2016AAA025). The authors wish to thank the technicians of School of Civil Engineering of Wuhan University for their help throughout the test process.

\section{References}

[1] L. C. Hollaway, "A review of the present and future utilisation of FRP composites in the civil infrastructure with reference to their important in-service properties," Construction and Building Materials, vol. 24, no. 12, pp. 2419-2445, 2010.

[2] Y. W. Zhou, Y. F. Wu, J. G. Teng, and A. Y. T. Leung, "Parametric space for the optimal design of compression-yielding FRPreinforced concrete beams," Materials and Structures/Materiaux et Constructions, vol. 43, no. 1-2, pp. 81-97, 2010.

[3] J.-G. Dai, Y.-L. Bai, and J. G. Teng, "Behavior and modeling of concrete confined with FRP composites of large deformability," Journal of Composites for Construction, vol. 15, no. 6, pp. 963973, 2011.

[4] W.-W. Wang, J.-G. Dai, and K. A. Harries, "Performance evaluation of RC beams strengthened with an externally bonded FRP system under simulated vehicle loads," Journal of Bridge Engineering, vol. 18, no. 1, pp. 76-82, 2013.

[5] J. G. Teng, J. F. Chen, S. T. Smith, and L. Lam, FRP strengthened RC structures, Wiley, Chichester, UK, 2002.

[6] Y. J. Kim, C. Shi, and M. F. Green, "Ductility and cracking behavior of prestressed concrete beams strengthened with prestressed CFRP sheets," Journal of Composites for Construction, vol. 12, no. 3, pp. 274-283, 2008.

[7] S. Li, T. Zhu, Y. Lu, and X. Li, "Effect of Temperature Variation on Bond Characteristics between CFRP and Steel Plate," International Journal of Polymer Science, vol. 2016, Article ID 5674572, 2016.

[8] Y.-W. Zhou, Y.-F. Wu, and Y. Yun, "Analytical modeling of the bond-slip relationship at FRP-concrete interfaces for adhesively-bonded joints," Composites Part B: Engineering, vol. 41, no. 6, pp. 423-433, 2010.

[9] Y. Y. Lu, W. J. Li, S. Li, X. Li, and T. Zhu, "Study of the tensile properties of CFRP strengthened steel plates," Polymer, vol. 7, no. 12 , pp. 2595-2610, 2015.

[10] J. Tatar and H. R. Hamilton, "Bond durability factor for externally bonded CFRP systems in concrete structures," Journal of Composites for Construction, vol. 20, no. 1, Article ID 04015027, 2016.

[11] M. I. Kabir, B. Samali, and R. Shrestha, "Fracture Properties of CFRP-Concrete Bond Subjected to Three Environmental 
Conditions," Journal of Composites for Construction, vol. 20, no. 4, Article ID 4016010, 2016.

[12] Z. Y. Ouyang, Durability of bond between FRP and concrete in moist environments: Experimental, numerical and analytical study [Ph.D. thesis], 2007.

[13] J. Zhou and J. P. Lucas, "Hygrothermal effects of epoxy resin. Part I: the nature of water in epoxy," Polymer Journal, vol. 40, no. 20, pp. 5505-5512, 1999.

[14] J. Tatar and H. R. Hamilton, "Effect of moisture exposure on the adhesive bond under direct shear," in Proceedings of the Proc. 7th Int. Conf. on FRP Composites in Civil Engineering (CICE 2014, International Institute for FRP in Construction (IIFC, Vancouver, Canada, 2014.

[15] S. Choi, A. L. Gartner, N. V. Etten, H. R. Hamilton, and E. P. Douglas, "Durability of concrete beams externally reinforced with CFRP composites exposed to various environments," Journal of Composites for Construction, vol. 16, no. 1, pp. 10-20, 2012.

[16] C. Tuakta and O. Büyüköztürk, "Conceptual model for prediction of FRP-concrete bond strength under moisture cycles," Journal of Composites for Construction, vol. 15, no. 5, pp. 743756, 2011.

[17] B. L. Wan, M. F. Petrou, and K. A. Harries, "The effect of the presence of water on the durability of bond between CFRP and concrete," Journal of Reinforced Plastics and Composites, vol. 25, no. 8, pp. 875-890, 2006.

[18] J. G. Dai, H. Yokota, M. Iwanami, and E. Kato, "Experimental investigation of the influence of moisture on the bond behavior of FRP to concrete interfaces," Journal of Composites for Construction, vol. 14, no. 6, pp. 834-844, 2010.

[19] T. Richardson, "Strengthening Damaged Reinforced Concrete Beams and Slender Columns Using Ultra-High Modulus CFRP Plates [M.S. Thesis]," Tech. Rep., 2013.

[20] P. Sadeghian and A. Fam, "Strengthening slender reinforced concrete columns using high-modulus bonded longitudinal reinforcement for buckling control," Journal of Structural Engineering (United States), vol. 141, no. 4, Article ID 04014127, 2015.

[21] C. Au and O. Büyüköztürk, "Peel and shear fracture characterization of debonding in FRP plated concrete affected by moisture," Journal of Composites for Construction, vol. 10, no. 1, pp. 35-47, 2006.

[22] K. Gamage, R. Al-Mahaidi, and B. Wong, "Fe modelling of CFRP-concrete interface subjected to cyclic temperature, humidity and mechanical stress," Composite Structures, vol. 92, no. 4, pp. 826-834, 2010.

[23] Codes for design of concrete structures, The Standardization Institute of Chinese Construction, China Planning Press, Beijing, China, 2010, GB 50010-2010.

[24] Standard Test Method for Tensile Properties of Polymer Matrix Composite Materials, ASTM, West Conshohocken, PA, USA, 2008, ASTM D3039-07.

[25] Y. Pan, G. Xian, and M. A. G. Silva, "Effects of water immersion on the bond behavior between CFRP plates and concrete substrate," Construction and Building Materials, vol. 101, pp. 326-337, 2015.

[26] K. Benzarti, S. Chataigner, M. Quiertant, C. Marty, and C. Aubagnac, "Accelerated ageing behaviour of the adhesive bond between concrete specimens and CFRP overlays," Construction and Building Materials, vol. 25, no. 2, pp. 523-538, 2011.

[27] E. H. Immergut and H. F. Mark, "Principles of plasticization," in Plasticization and plasticizer processes, N. A. J. Platzer, Ed., vol. 48 of Advances in Chemistry, pp. 1-26, American Chemical Society, Washington DC., USA, 1965.

[28] J. Shrestha, T. Ueda, and D. Zhang, "Durability of FRP concrete bonds and its constituent properties under the influence of moisture conditions," Journal of Materials in Civil Engineering, vol. 27, no. 2, Article ID A4014009, 2015.

[29] J. Shrestha, D. Zhang, and T. Ueda, "Durability performances of carbon fiber-reinforced polymer and concrete-bonded systems under moisture conditions," Journal of Composites for Construction, vol. 20, no. 5, Article ID 04016023, 2016.

[30] H. Saadatmanesh, M. Tavakkolizadeh, and D. Mostofinejad, "Environmental effects on mechanical properties of wet lay-up fiber-reinforced polymer," ACI Materials Journal, vol. 107, no. 3, pp. 267-274, 2010.

[31] S. Li, J. Hu, and H. Ren, "The combined effects of environmental conditioning and sustained load on mechanical properties of wet lay-up fiber reinforced polymer," Polymer, vol. 9, no. 7, article no. 244, 2017.

[32] J. G. Dai, T. Ueda, and Y. Sato, "Development of the nonlinear bond stress-slip model of fiber reinforced plastics sheet-concrete interfaces with a simple method," Journal of Composites for Construction, vol. 9, no. 1, pp. 52-62, 2005.

[33] J. Dai, T. Ueda, and Y. Sato, "Unified analytical approaches for determining shear bond characteristics of FRP-concrete interfaces through pullout tests," Journal of Advanced Concrete Technology, vol. 4, no. 1, pp. 133-145, 2006. 


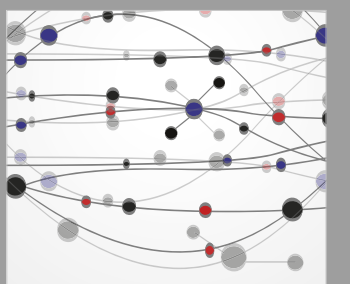

The Scientific World Journal
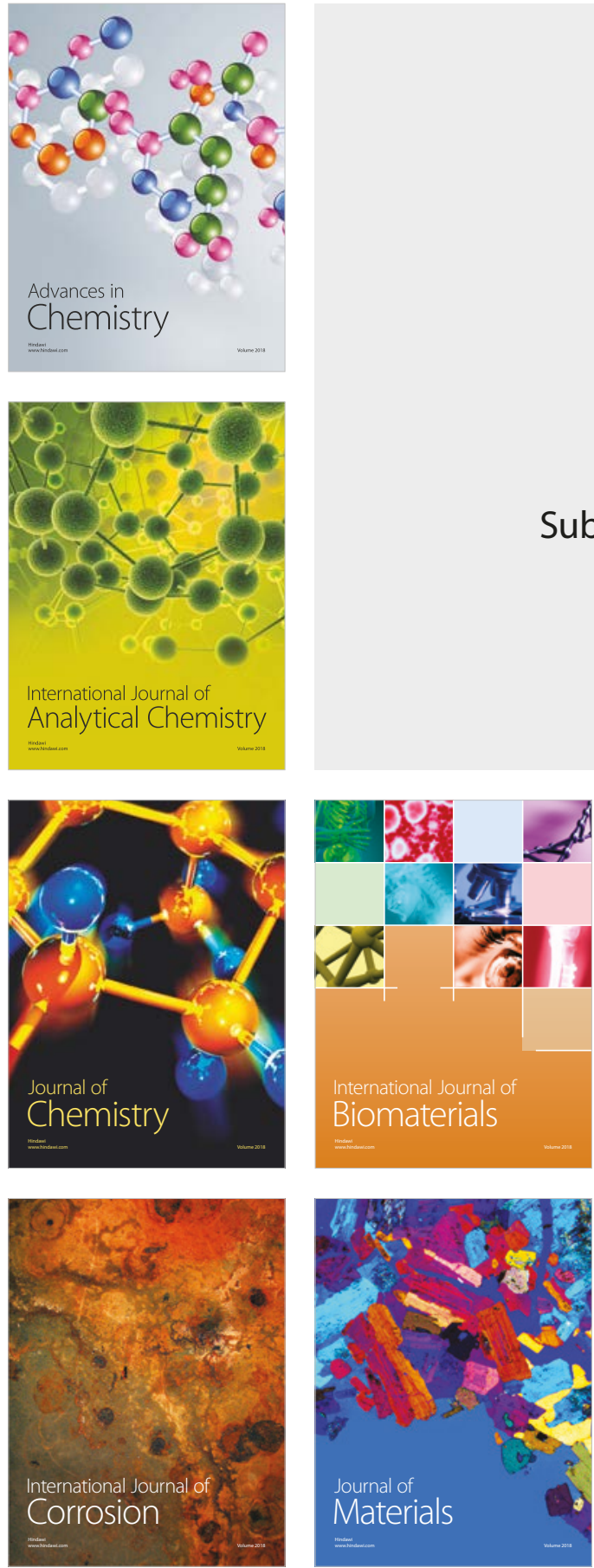

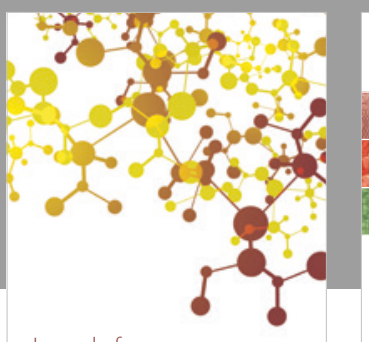

Journal of

Applied Chemistry
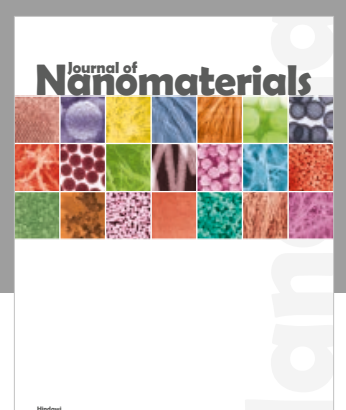

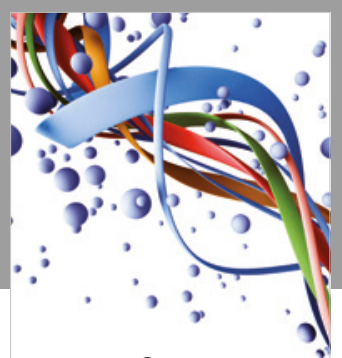

Scientifica

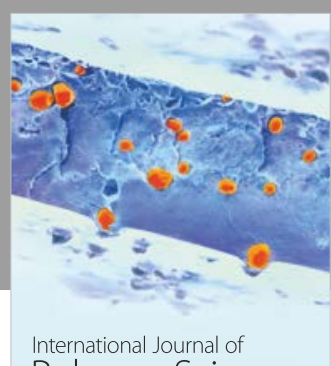

Polymer Science

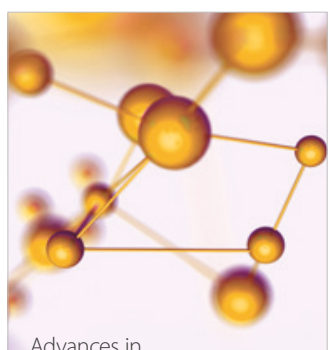

Physical Chemistry
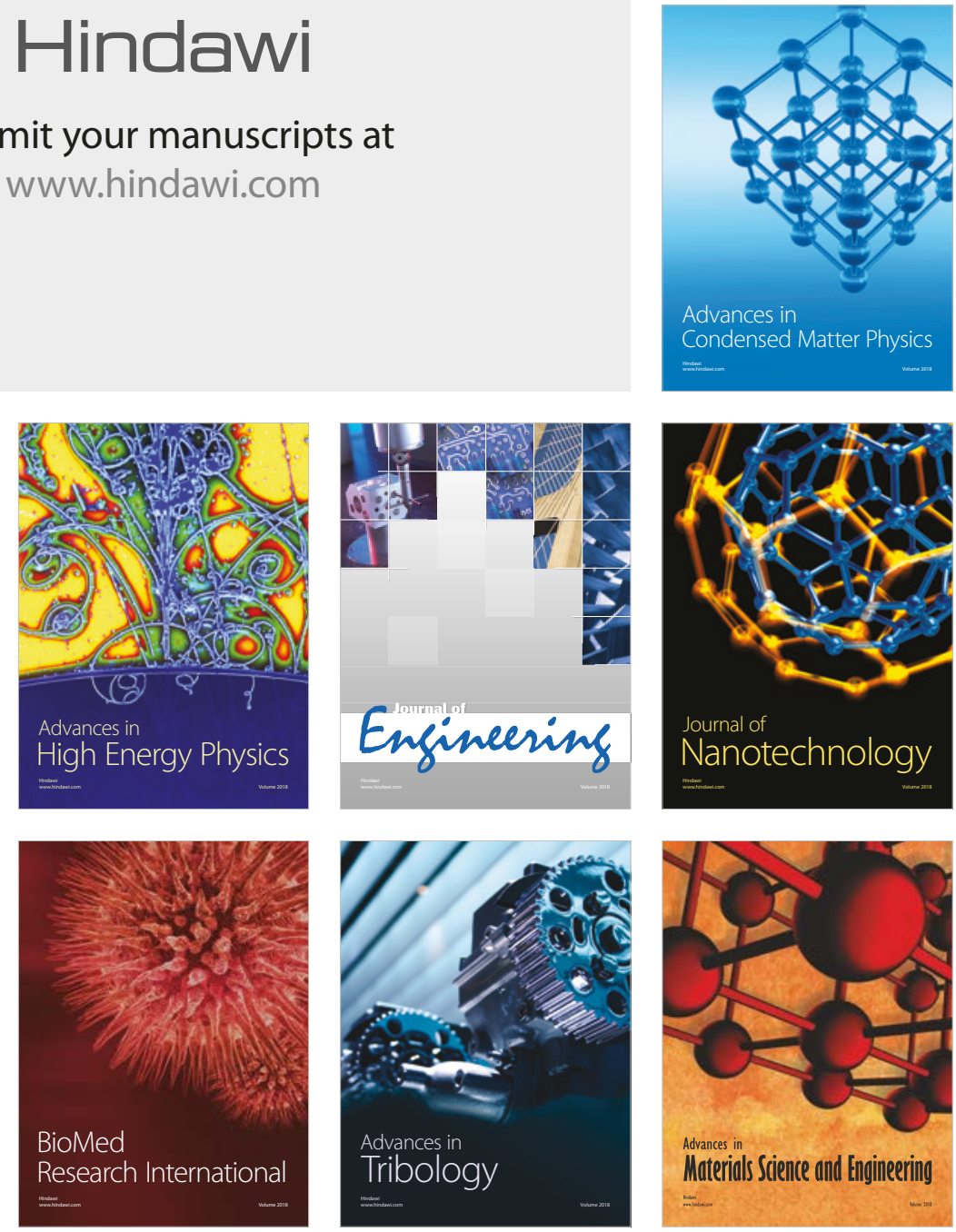